\title{
Research on the Performance Measurement of Green Supply Chain Management in China
}

\author{
Yan Li \\ School of Management, Xi' an University of Science and Technology \\ Xi'an 710054, Shaanxi, China \\ Tel: 86-13379068828Ｅ-mail: lili14103@126.com
}

Received: February 20, 2011

Accepted: March 20, 2011

doi:10.5539/jsd.v4n3p101

This study is financed by the National Natural Science Funds of China (No: 70673079), Education Department of Shaanxi Provincial Government (No:11JK0061) and Young Teacher's Funds of Xi'an University of Science and Technology (No:J10008,GJY-2009-YB-10, GJY-2010-PY-1, JG08029,JG08010).

\begin{abstract}
As a developing country, economic and environmental performance has to be balanced in china. Green supply chain management (GSCM) is emerging to be an important approach for Chinese enterprises to improve performance, possibly on both dimensions. Based upon a database of over 128 manufacturing facilities in china, this paper explored performance measurement for GSCM. The results showed that GSCM was strongly complementary to other advanced management practices, and contributed to improving environmental performance.
\end{abstract}

Keywords: Performance measurement, GSCM, Supply chain

\section{Introduction}

Today's business environment is characterized by increasing uncertainties. GSCM has emerged as an important new approach for enterprises to achieve profit and market share objectives by reducing environmental risk and impact. In supply chains with multiple vendors, manufacturers, distributors and retailers, whether regionally or globally dispersed, performance measurement is challenging because it is difficult to attribute performance results to one particular entity within the chain. Performance measurement in supply chains is difficult for additional reasons, especially when looking at numerous tiers within a supply chain, and green supply chain management performance measurement is virtually non-existent. With these barriers and difficulties in mind, GSCM is needed for a number of reasons (including regulatory, marketing and competitiveness reasons). Overcoming these barriers is not a trivial issue, but the long-term sustainability (environmental and otherwise) and competitiveness of organizations may rely on successful adoption of GSCM (Sharfman, 2009).

In this paper was aimed to examine the adoption levels of GSCM practices in China. Previous investigations completed an exploratory analysis that identified 25 factors of GSCM practices and performance. These factors were then examined for relationships between adoption of GSCM eventual performance outcomes incorporating moderation effects of quality management and just-in-time practices. Using data from 128 usable organizational responses, factor analysis was used to analyze the large data . The result indicated that eco-design level improved performance. Our findings are important for decision makers because they highlight the important of matching GSC to the requirements of the environment.

To address the numerous issues facing GSCM, this paper begins with a general discussion of GSCM and performance measurement. Then, presentation of some principles of GSCM will set the stage for the discussion of GSCM and environmental management systems. Metrics and measures are identified within this context. Management and research issues related to the management of GSCM systems conclude our discussion.

\section{Literature review}

\subsection{Several studies for performance measurement}

Several studies have investigated the universal principles of performance measurement (Adams et. al 1995). Even though significant work has been completed on performance measurement and management on internal organizational operations, the emphasis on supply chain performance measurement (especially with an 
inter-organizational focus), in either the practitioner or research community, has been relatively limited (Gunasekaran et. al 2004) .Extending this work, Beamon and Chen examine the effects of the various factors on supply chain performance and identify the nature of the relationship between these factors and overall supply chain performance. Brewer and Speh posit a number of concerns in applying performance measurement tools and systems across the supply chain (Beamon and Chen 2001).

\subsection{The existing performance measurement tool}

The existing performance measurement tool set for environmental operations is growing, but may not yet be adequate to fully assess GSCM. Tools, from the literature and practice, include such items as the analytical hierarchy process, activity-based costing, balanced scorecard, and life cycle analysis type tools. Some tools have seen, or could be, directly applied to aspects of GSCM and performance, and others require adjustments and extensions.

The analytical hierarchy process is a benefit measurement model integrating subjective managerial inputs and data with tangible quantifiable information on multiple criteria as a decision support model helping managers understand the trade-offs between environmental dimensions (Tachizawa 2007).Yet, the extension of analytical hierarchy process beyond dyadic organizational boundaries to further supply chain evaluation has not been completed. Issues relating to incorporating management judgment from across organizational boundaries in the analytical hierarchy process need to be advanced.

Life cycle analysis (LCA) model emphasizes the close linkage between life cycle analysis and GSCM methods (Naim et. al 2006). The core aspect of this an assessment matrix that scores various emissions stressors and data confidence values for six major steps within an organization's individual supply chain including, material acquisition, pre-production, production, use, distribution and disposal. Maps are an output of this process and graphically represent the values of the environmental impacts along the supply chain. The tool can evaluate various products for comparison, but it is not clear the tool's applicability extends to multiple partners within the supply chain. The scoring methodology may also be rather subjective on many dimensions.

The balanced scorecard is another popular tool within the corporate performance management literature. It is a management/measurement system purporting to aid organizations develop corporate visions, strategy and cascading them into action. It provides feedback on internal business processes and external outcomes in order to continuously improve strategic performance and results. The balanced scorecard suggests organizational performance be viewed from four perspectives, and to develop metrics, collect data and analyze the organization relative to each of these perspectives.

Overall, there is no one perfect tool for a GSCM (which in itself is a tool), but similar to any tools that are to be used for planning, assessment, and management, their usage is heavily dependent on agreement across organizations and the ease and accessibility of data and knowledge to apply these tools. Elements of these efforts are central to total quality and continuous improvement programs, where performance measurement is critical to any organization in managing their operations. Performance measurement has many uses including the determination of the efficiency and effectiveness of an existing system or to compare competing alternative systems. Performance measurement is typically used to plan design, implement and monitor proposed systems.

\subsection{Gscm concept model}

Green supply chain management has considered the supply chain of various links of environmental problem and paid attention to environmental protection and to promote coordinated development of economy and environment. Judging from the composition of green supply chain, participate in the green supply chain of basic are mainly suppliers, manufacturers, distributors and retailers enterprise and end users. Its core is keeping a watchful eye on resources and environment and improving traditional supply chain from the angle of environment. So as to form a symbiotic model of the supply chain system, mainly through using green technology application and building reverse supply chain to extend the traditional supply chain and then to form a closed loop. At the micro-level, enterprise longitudinally extends the production chain from extending production goods to waste processing and regeneration. On transverse technical system, it will recycle and make use of waste and do innocent treatment as well. At the macro-level, make the technical system of the whole society achieve networking and make resources achieve recycling. So as achieve comprehensive innocent treatment to the waste.

\subsection{Critical factors for GSCM practices}

A number of critical factors for implementing GSCM practice have been proposed. These strategies are aimed at mitigating the risks associated with supply chain interruptions or delays, and protecting a company's reputation 
and brand image from damaging public controversies. Critical factors for GSCM practices have been identified by various authors; they are briefly outlined below and summarized as Table1.

\section{Methodology}

Data collection occurred in three phases including a pilot test, convenience surveys and a random survey, whose results were eventually aggregated.

Pilot test: We initially completed a pilot test to validate and refine the measurement instrument, i.e., a survey questionnaire. A pilot test was conducted for managers on environmental management. Based on the suggestions from 28 respondents, we made minor modifications to the survey questionnaire.

Convenience surveys: The second stage involved the application of convenience surveys. To minimize the possibility of misunderstanding the questionnaire items by respondents, we drew a convenience sample of the participants in workshops offered in the School of Management at the Xi'an University of Technology.

Random survey: The third stage of data acquisition was an administration of the survey via postal mail with follow-up telephone calls. We carried out a random survey in this stage. Due to the difficulties in data collection from all regions within China, the random survey was conducted in Xi'an. Out of a total of 600 questionnaires mailed, 128 usable organizational responses were received from manufacturing enterprises.

Sample aggregation: Overall, a total of 300 responses were received. Multiple responses from the same manufacturer were aggregated into one usable organizational response. The targeted samples and respondents of this study possess managerial experience at the middle and upper management levels.

This implies that the sample proportion of response rate of this study is acceptable, and it reflects the virtue of novel issue of GSCM practice. Collected data were analyzed using statistical software SPSS Version 10.0 and both factor analysis and reliability testing were carried out to identify the critical factors for GSCM performance management.

\section{Data analysis and results}

\subsection{Profile of respondents}

The first step was selecting GSCM capability attributes by reviewing the literature on green/environmental logistics and supply chain management research. This was followed by the design of the questionnaire, personal interviews with GSCM practitioners, and a content validity test. The questionnaire design followed the stages outlined by Churchill (Churchill 1999). Information sought was first specified and then the following issues were settled: questionnaire type and its method of administration, the content of individual questions form of response to and wording of each question, sequence of questions, and physical characteristics of the questionnaire. Their ownership and company size is showed that the highest percentage of respondents is from state-owned (75.0 percent), follow by joint ventures ( 15 percent), private (10.0 percent).Regarding the size of the respondents, it ranged from under 500 to over 3,000 employees which found that respondent's enterprises are mainly from less than 500 to more than 3,000 .

\subsection{Identification of critical factors using factor analysis}

An exploratory factor analysis was conducted to analysis the performance of GSCM from the survey data. Factors were extracted using the maximum likelihood method, followed by a varimax rotation as shown in table 1. The Kaiser criterion (eigenvalues $>1$ ) was employed in conjunction with an evaluation of scree plots. Bartlett's test of sphericity and the Kaiser-Meyer-Olkin (KMO) measure of sampling adequacy were employed to test the appropriateness of the data for factor analysis. The test results of KMO show that the compared value is 0.763 , significantly exceeding the suggested minimum standard of 0.5 required for conducting factor analysis. Based on the above tests, it is evident that all factors are suitable for applying factor analysis. The authors performed factor analysis to extract factors in accordance with the values of discontinuity greater than 1 ; and factor loading exceeding 0.6 was principle in choosing factors. The five variables were eliminated because their factor loadings were less than 0.07.The remaining 20 items, therefore, were re-analyzed and extracted into seven dimensions, which denominated Green design ability, Green purchasing ability, Green manufacturing capacity, Green marketing and purchasing power, Recycling products processing ability, Level of information technology and Comprehensive level as shown in Table 2.

\subsection{Reliability and validity analysis}

Reliability concerns the extent to which an experience, test or any measuring procedure yields the same results on repeated trials (Carmines and Zeller 1979). The reliability of the factors needs to be determined to support any measures of validity that may be employed. Both reliability tests and item analysis were recalculated without 
those five items. Table 2 lists the new Cronbach's alpha values, ranging from 0.8642 to 0.9442 , after the five items were dropped. Generally, Cronbach's alpha value exceeding 0.7 is considered to have high internal consistency of scale (Nunnally 1978). All the Cronbach's alpha values in our study are greater than 0.7 , revealing the high internal consistency. Content validity depends on how well the researchers create measurement items to cover the content domain of the variable being measured (Handfield et. al 2002). The content validity of the questionnaire in this work is based on an exhaustive literature review and detailed evaluations by five GSCM process assurance and two external environment assurance. The five GSCM process assurance was labeled as Eco-design level, green purchasing level, green manufacturing capacity, green marketing and consumption, and recycling products processing ability. The two external environment assurance were labeled as Level of information technology and Comprehensive level. Consequently, we are confident that the critical factors constructed by the factor analysis have content validity. Less criterions were designed to explore the correlation with the performance for GSCM. The results of this study may provide a better understanding and help identify the opportunities of GSCM implementation.

\subsection{Summary of empirical findings}

After obtaining satisfactory results in both the reliability and validity tests, we calculated the mean value for each of the five GSCM factors. Manufacturers in our samples have on average initiated three GSCM practices, namely, Top management support, Product testing report, Green purchasing with mean values of 4.67, 4.51 and, 4.50 , respectively. The analytical results demonstrate that top management support is the most important item for the successful implementation of GSCM practice in china. Many supply chain management and environmental professionals in leading companies noted that the understanding of the top management of the value and support for their efforts made a critical difference to the success of their GSCM programs. The results also indicated that product testing reports is also equally important for enterprises to ensure that supplier provided products are environmentally friendly. Currently, wide-ranging approaches to supplier management for companies in China embrace testing report as requirements essential to assuring that products do not contain hazardous substances, as this approach can recognize the responsibility when products violate environmental legislation. At last, In Chinese companies had a higher mean value for green purchasing. The recent emergence of purchasing as an important participant in the corporate sustainable enterprise debate is the result of the convergence of several developments that have highlighted the purchasing role in effective environmental management (Lamming and Hampson 1996). In GSCM practice, purchasing was involved in the activities of reduction, recycling, reuse and materials substitution, which are all necessary to lead and facilitate the GSCM implementation. The results of this investigation show that practicing green purchasing can ensure product environmental quality. It can enable firms to provide design specifications to suppliers that include environmental requirements for purchased items, and can collaborate with suppliers to provide materials, equipment, parts and services that support environmental goals (Molina-Azorin, 2009). However, the sample manufacturers have on average only started to consider collaboration on products recycling with the same sector industry and green consumption with mean values of 3.43 and 3.67, respectively, a bias to favor more internally focused practices in their adoption of GSCM. In china, most companies are state-owned, which is also the case for our data set where 96 of 128 companies are state-owned, representing $75 \%$ of the samples. Even so, Companies in China have started to integrate environmental concerns into treatment and recovery of waste equipment and made producers responsible for financing these activities. The traditional consumption idea breached the harmonious rule of human and nature during industrial civilization era,which threatened human subsistence and development; the green consumption idea appeal to negate the traditional production and consumption drastically,and change fetishism to excessive physical consumption, and advocate prolific spiritual living. Therefore, we should sparkplug the green consumption idea, and accelerate the harmony of human and nature, and actualize sustainable development stratagem,which is an inevitable selection that human give into future.

Table 2 provides a summary of the means and standard deviations for all 20 measurement items on the adoption of GSCM practices. It should be noted that all items on level of information technology have attained mean values over 4.00 .

Companies should provide clear, consistent and frequent communication about environmental issues with their suppliers and other partners in the green supply chain. To do so, suppliers must understand how to carry out the green initiatives of GSCM in accordance with the requirements of clients. Information technology is necessary because the GSCM involves various and complex issues. Hence, an internal communication platform is needed not only to raise the awareness of their employees on GSCM but also to eliminate the barriers in the successful implementation of the GSCM. 


\section{Conclusions}

Recently, Chinese enterprises have increased their environmental awareness due to regulatory, competitive, and marketing pressures and drivers. Chinese enterprises highlight their exporting philosophies by pursuing such international organizational standards as ISO9000 serial and ISO14001 certification. At the same time, in support of our second proposition, Chinese enterprises have sought to implement a variety of GSCM practices to improve their environmental performance in response to this export philosophy so that they can more effectively serve as suppliers to foreign enterprises in China. Internal environmental management, especially commitment from top-level managers and support from mid-level managers, will be necessary for development of any GSCM programs in China. This is not different from any enterprise almost any place in the world. Thus, education (raising awareness) of management in GSCM practices is one of the initial crucial steps in this arena.

However, GSCM is still in its infancy in China. Chinese enterprises have recognized its importance, but have lagged in the implementation of these principles into practice. It is not clear what the barriers are for this implementation, but the lack of necessary tools, management skills and knowledge, and most likely the lack of an economic justification in terms of performance, may all be barriers. Therefore, even with higher environmental awareness and pressures in Chinese enterprises, this awareness has not translated into strong GSCM practice adoption, let alone to improvements expected in some areas of performance. It seems that the Chinese government has stipulated new policies to promote GSCM and other corporate environmental practices primarily to export more products and to attract more foreign investments. For example, some local government agencies have helped enterprises to pass ISO14001 certification by providing training and subsidizing part of certification fee. To realize both environmental and economic performance, investment recovery by altering current policies and establishing recovery system infrastructures that help "close the loop" is something that should be highlighted by Chinese national policy makers.

This work is one of the few efforts to investigate GSCM practices in China. Thus, our investigation and its findings are still relatively exploratory. Future research can also include investigation of longitudinal relationships identified in this work and can help identify long-term patterns in one of the world's largest countries and one that will truly have a global impact on the environmental and economic direction of society over the next few decades.

Despite the limited research and relative novelty of GSCM in China, efforts made by Chinese enterprises together with the Chinese government have established a good foundation for further development. After China's entry into the WTO, more foreign enterprises have established joint ventures or FDI enterprises in China. By improving both quality and environmental image, Chinese enterprises can cooperate with foreign enterprises in China such as becoming long-term suppliers of their foreign customers. This is a road that may also improve operations and business performance for these organizations. Win-win is still possible at the national and organizational level if GSCM practices are seriously given consideration.

\section{References}

Adams, S., Sarkis, J. and Liles, D. (1995). The evelopment of strategic performance metrics, Engineering Management Journal,Vol.7 No.1,24-32.

Beamon, B. and Chen, V. (2001). Performance analysis of conjoined supply chains, International Journal of Production Research, Vol.39 No.14,pp.3195-218.

Carmines, E. and Zeller, R. (1979). Reliability and Validity Assessment, Series: Quantitative Applications in Social Science, Sage Publications, Newbury Park, CA.

Churchill, G. A. (1991). Marketing Research: Methodological Foundation, fifthed. The Dryden Press, New York.

Gunasekaran, A., Patel, C. and Mc Gaughey, R.E. (2004). A framework for supply chain performance measurement, International Journal of Production Economics, Vol.87 No.3,pp.333-47

Handfield, R., Walton, S. V., Sroufe, R. and Melnyk, S.A. (2002). Applying environmental criteria to supplier assessment: a study in the application of the analytical hierarchy process, European Journal of Operational Research, Vol.141 No.16, pp.70-87.

Lamming, R. and Hampson,J. (1996). The environment as a supply chain management issue, British Journal of Management, Vol.7 No.1, pp.S45-62.

Molina-Azorin, J.F., Claver-Cortes, E., Pereira-Moliner, J., Tar1, J.J. (2009). Environmental practices and firm performance: an empirical analysis in the Spanish hotel industry. Journal of Cleaner Production 17, 516-524.

Naim, M. M., Potter, A. T., Mason, R.J., Bateman, N. (2006). The role of transport flexibility in logistics 
provision. The International Journal of Logistics Management , 17,297-311.

Nunnally, J. (1978), Psychometric Theory, 2nd ed., McGraw-Hill, New York, NY.

Sharfman, M.P., Shaft, T.M., Anex, R.P. (2009). The road to cooperative supply-chain environmental management: trust and uncertainty among pro-active firms. Business Strategy and the Environment 18, 1-13.

Tachizawa,E.M.,Thomsen,C.G.,nez. (2007). Drivers and sources of supply flexibility: an exploratory study. International Journal of Operations \& Production Management, 27,1115-1136.

Table 1. Critical factors for GSCM practices

\begin{tabular}{|c|c|}
\hline Criteria factors & Item description \\
\hline CF1 & Suppliers environmental questionnaire \\
\hline $\mathrm{CF} 2$ & Compliance statement \\
\hline $\mathrm{CF} 3$ & Product testing report \\
\hline $\mathrm{CF} 4$ & BOM \\
\hline CF5 & $\begin{array}{c}\text { Establishing environmental requirements for } \\
\text { purchasing items }\end{array}$ \\
\hline CF6 & Green purchasing \\
\hline CF7 & Information system \\
\hline CF8 & Joining local recycling organizations \\
\hline CF9 & $\begin{array}{l}\text { Collaboration on products recycling with the } \\
\text { same sector industry }\end{array}$ \\
\hline CF10 & Produce disassembly manuals \\
\hline CF11 & Green design \\
\hline CF12 & Top management support \\
\hline CF13 & Environmental policy for GSCM \\
\hline CF14 & Cross-function integration \\
\hline CF15 & Manpower involvement \\
\hline CF16 & $\begin{array}{l}\text { Effective communication platform within } \\
\text { companies and with suppliers }\end{array}$ \\
\hline CF17 & $\begin{array}{c}\text { Establish a environmental risk management } \\
\text { system for GSCM }\end{array}$ \\
\hline CF18 & Supplier evaluation and selection \\
\hline CF19 & Applying LCA to carry out eco-report \\
\hline CF20 & Establish an environmental database of products \\
\hline $\mathrm{CF} 21$ & Cooperation with customer for green packaging \\
\hline CF22 & Transport greening \\
\hline CF23 & Consumer greening \\
\hline
\end{tabular}


Table 2. GSCM performance measurement factor analysis results

\begin{tabular}{|c|c|c|c|c|c|c|c|}
\hline Dimension & $\begin{array}{l}\text { Index } \\
\text { layer }\end{array}$ & Mean & $\mathrm{SD}$ & $\begin{array}{l}\text { Item loading } \\
\text { range }\end{array}$ & $\begin{array}{l}\text { Eigen- } \\
\text { values }\end{array}$ & $\begin{array}{l}\text { Cumulative } \\
\text { percentage }\end{array}$ & $\begin{array}{l}\text { Cronbach's } \\
\text { alpha }\end{array}$ \\
\hline \multirow[t]{3}{*}{ Eco-design level (B1) } & CF3 & 4.51 & 0.77 & 0.725 & \multirow[t]{3}{*}{3.526} & \multirow[t]{3}{*}{54.28} & \multirow[t]{3}{*}{0.9361} \\
\hline & CF4 & 3.78 & 0.78 & 0.645 & & & \\
\hline & CF11 & 4.32 & 1.09 & 0.811 & & & \\
\hline \multirow{4}{*}{$\begin{array}{c}\text { Green purchasing level } \\
\text { (B2) }\end{array}$} & CF2 & 4.12 & 1.08 & 0.574 & \multirow[t]{4}{*}{2.312} & \multirow[t]{4}{*}{57.14} & \multirow[t]{4}{*}{0.8642} \\
\hline & CF5 & 4.21 & 0.94 & 0.882 & & & \\
\hline & CF6 & 4.50 & 0.72 & 0.714 & & & \\
\hline & CF18 & 4.41 & 0.67 & 0.698 & & & \\
\hline \multirow{3}{*}{$\begin{array}{l}\text { Green manufacturing } \\
\text { capacity }(\mathrm{B} 3)\end{array}$} & CF10 & 4.08 & 0.76 & 0.632 & \multirow[t]{3}{*}{1.097} & \multirow[t]{3}{*}{60.25} & \multirow[t]{3}{*}{0.9442} \\
\hline & $\mathrm{CF} 24$ & 4.14 & 0.83 & 0.754 & & & \\
\hline & $\mathrm{CF} 25$ & 3.98 & 0.93 & 0.785 & & & \\
\hline \multirow{3}{*}{$\begin{array}{l}\text { Green marketing and } \\
\text { consumption (B4) }\end{array}$} & CF21 & 4.21 & 0.87 & 0.963 & \multirow[t]{3}{*}{2.605} & \multirow[t]{3}{*}{61.23} & \multirow[t]{3}{*}{0.8684} \\
\hline & CF22 & 3.76 & 1.12 & 0.862 & & & \\
\hline & CF23 & 3.67 & 1.08 & 0.754 & & & \\
\hline \multirow{2}{*}{$\begin{array}{c}\text { Recycling products } \\
\text { processing ability (B5) }\end{array}$} & CF8 & 3.85 & 0.97 & 0.867 & \multirow[t]{2}{*}{1.356} & \multirow[t]{2}{*}{53.21} & \multirow[t]{2}{*}{0.9123} \\
\hline & CF9 & 3.43 & 0.89 & 0.785 & & & \\
\hline \multirow{3}{*}{$\begin{array}{l}\text { Level of information } \\
\text { technology (B6) }\end{array}$} & CF16 & 4.04 & 0.77 & 0.843 & \multirow[t]{3}{*}{2.423} & \multirow[t]{3}{*}{57.45} & \multirow[t]{3}{*}{0.9012} \\
\hline & CF17 & 4.09 & 0.75 & 0.772 & & & \\
\hline & CF19 & 4.03 & 0.94 & 0.931 & & & \\
\hline \multirow{2}{*}{$\begin{array}{l}\text { Comprehensive level } \\
\text { (B7) }\end{array}$} & CF12 & 4.67 & 0.92 & 0.892 & \multirow[t]{2}{*}{3.324} & \multirow[t]{2}{*}{60.32} & \multirow[t]{2}{*}{0.8756} \\
\hline & CF13 & 4.43 & 0.87 & 0.785 & & & \\
\hline
\end{tabular}

